\title{
Study on the Applicability of Short Fiber Reinforced Concrete to Precast Concrete Slabs for Slab Track
}

\author{
Takatada TAKAHASHI \\ Researcher,
}

\section{Etuo SEKINE, Dr. Eng.}

Senior Researcher, Laboratory Head,
Takahiro HORIIKE

Senior Researcher,

Track Structures \& Geotechnology, Track Technology Division

\author{
Shigeru MATSUOKA \\ Tekken Co., Ltd.
}

\author{
Hideki HOSHIRO \\ Kuraray Co., Ltd.
}

\begin{abstract}
Recently, concern has been raised about rebar corrosion of precast concrete slabs. There is strong demand for durable precast concrete in the railway operators, and to meet this requirement, the authors have proposed applying the short fiber reinforced concrete without rebar to precast concrete slabs. In order to identify the effectiveness of the proposal, the influence which the kind and the amount of mixing of the fiber on the flow property and the bending toughness of concrete was examined. Furthermore, analytical and experimental study on the bending fatigue was carried out. The results of the experiment had good agreement on those of the analysis, and we were able to demonstrate the behavior of the fracture process in the concrete.
\end{abstract}

Keywords: precast concrete slab, short fiber reinforced concrete, flowability, bending toughness, tension softening curve, fatigue design

\section{Introduction}

The practical adequacy of concrete slab track (Fig1) was first confirmed on the Sanyo Shinkansen, and now this type of track is adopted as about $90 \%$ of the main track structure of newly constructed Shinkansen. Some of the concrete slab tracks have been used for 30 years or more. Damage to the precast concrete slabs caused by the dynamic train loads excited by passing trains has not been reported up to now, however, damage of precast concrete slabs due to environmental conditions is becoming a problem. In particular, salt damage in undersea tunnels and frost damage in cold districts are of great concern to us. Salt damage can be observed in various parts of Japan, and salt damage in the precast concrete slabs with thin concrete cover will be focused on. We have therefore suggested applying short fiber reinforced concrete without rebar to the precast concrete slabs. We think that, in this way, we can develop precast concrete slabs with sufficient durability.

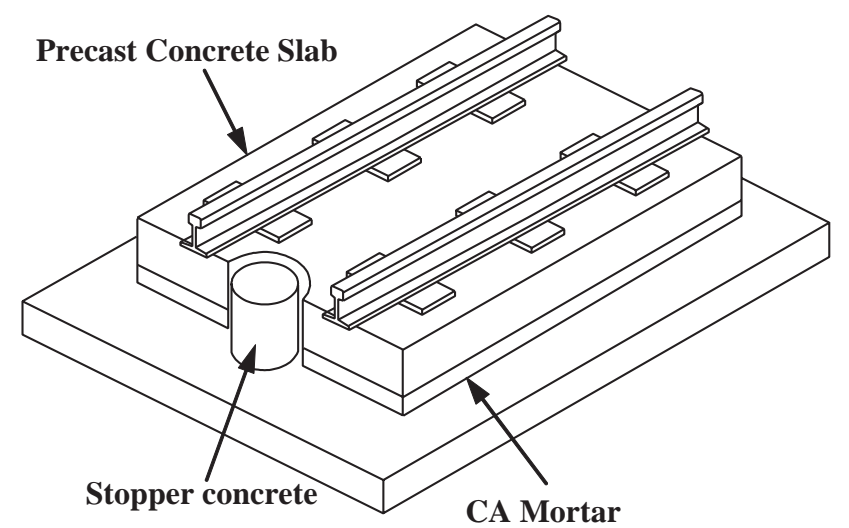

Fig. 1 Schematic view of slab track
This paper describes test results about the flow and strength property of short fiber reinforced concrete, and the evaluation method about its bending fatigue.

\section{Material property of short fiber reinforced concrete}

\subsection{Short fiber}

By mixing many short fibers in concrete, concrete becomes a tough material because the short fibers have a function of transmitting stress between the cracks in the concrete. Hence, if a precast concrete slab is fabricated with fiber reinforced concrete, many short fibers will control the growth of cracking due to frost damage, and rebar corrosion due to salt damage will not take place.

The short fibers used in our study are the polypropylene, hereinafter referred to as PP, short fiber and polyvinyl alcohol, hereinafter referred to as PVA, short fibers which are shown in Fig. 2. Table 1 gives the physical properties of each short fiber. These short fibers are mainly used for concrete. The PVA short fiber has good adhesion with concrete because of its hydrophilic property, and its specific gravity is larger than water. The PP short fiber needs the surface treatment for improving adhesion with

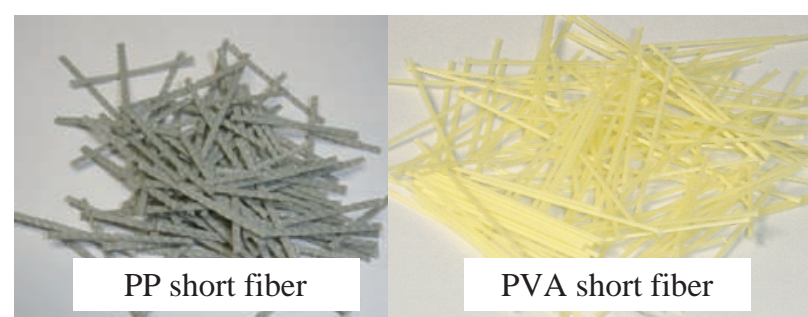

Fig. 2 Appearance of a short fiber 
Table 1 Physical properties of a short fiber

\begin{tabular}{|c|c|c|c|c|c|c|}
\hline & Density & $\begin{array}{c}\text { Cross-Sectional } \\
\text { shape }\end{array}$ & Length & \multirow{2}{*}{ Aspect ratio } & $\begin{array}{c}\text { Tensile } \\
\text { strength }\end{array}$ & $\begin{array}{c}\text { Tensile } \\
\text { elastic }\end{array}$ \\
\cline { 2 - 4 } \cline { 6 - 7 } & $\mathrm{g} / \mathrm{cm}^{3}$ & $\mathrm{~mm}$ & $\mathrm{~mm}$ & & $\mathrm{~N} / \mathrm{mm}^{2}$ & $\mathrm{kN} / \mathrm{mm}^{2}$ \\
\hline PP & 0.91 & $0.5 \times 1.0$ & 30 & 38 & 530 & 10.5 \\
\hline PVA & 1.30 & $\varphi 0.660$ & 30 & 45 & 880 & 29 \\
\hline
\end{tabular}

Table 2 Mix proportion of the concrete

\begin{tabular}{|c|c|c|c|c|c|c|}
\hline \multirow{2}{*}{$\begin{array}{c}\text { W/C } \\
(\%)\end{array}$} & \multicolumn{6}{|c|}{ Unit quantity $\left(\mathrm{kg} / \mathrm{m}^{3}\right)$} \\
\cline { 2 - 7 } & Water & Cement & $\begin{array}{c}\text { Fine } \\
\text { aggregate }\end{array}$ & $\begin{array}{c}\text { Coarse } \\
\text { aggregate }\end{array}$ & $\begin{array}{c}\text { AE and high-range } \\
\text { water-reducing admixture }\end{array}$ & $\begin{array}{c}\text { AE } \\
\text { admixture }\end{array}$ \\
\hline 47 & 180 & 383 & 904 & 750 & 4.98 & 0.0306 \\
\hline
\end{tabular}

concrete because of its hydrophobicity, and its specific gravity is smaller than water.

\subsection{Flow property of short fiber reinforced concrete}

When many short fibers are mixed in concrete, the flow property of short fiber reinforced concrete may become worse because the aspect ratio of a short fiber is much larger than that of aggregate which is a granular shape [1], and the aggravation of flow property will lead to construction becoming more difficult. Then, we examined the slump flow, hereinafter referred to as SF, before and after mixing many short fibers based on JIS A 1101 in order to study the variation of flow property.

The mixing proportion of the concrete used for the flow property measurement is shown in Table 2 . We set SF before mixing many short fibers in concrete to $55 \mathrm{~cm}$ as a target in consideration of the degradation of the flow property, and the air content before mixing many short fibers in concrete to $7 \%$ as a target so that they may be easily mixed in the concrete. The actual average values of SF and air content were $58.2 \%$ and $6.7 \%$ respectively, and were almost the same values as the target values. The amount of short fiber was adopted as the parameter for the experiment, and the mixing rate of short fiber per volume was set to $0.5,1.0,1.5,2.0$, and 3.0 vol.\%.

In order to examine the change of SF, we defined the $\mathrm{SF}$ change ratio as shown in the Equation (1).

$$
\text { SF change ratio }=\frac{S F \text { after mixing }}{\text { SF before mixing }}
$$

Figure 3 shows the SF of the short fiber reinforced concrete having the mixing rate of 2.0 vol.\% of the PVA short fiber. And Fig. 4 shows the relationship between the SF change ratio and the mixing rate of the short fibers. From these figures, we have confirmed that the flow property sufficient for construction could be secured by

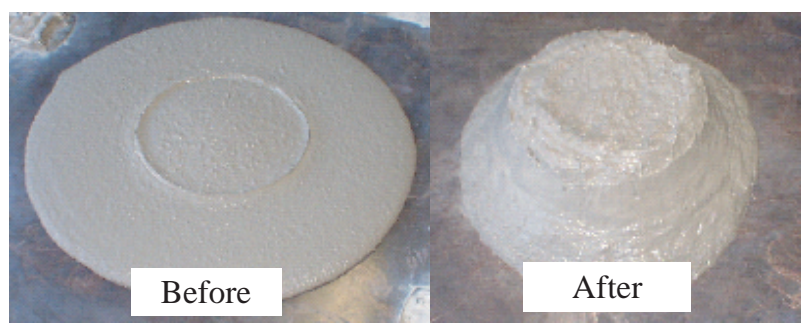

Fig. 3 Slump flow

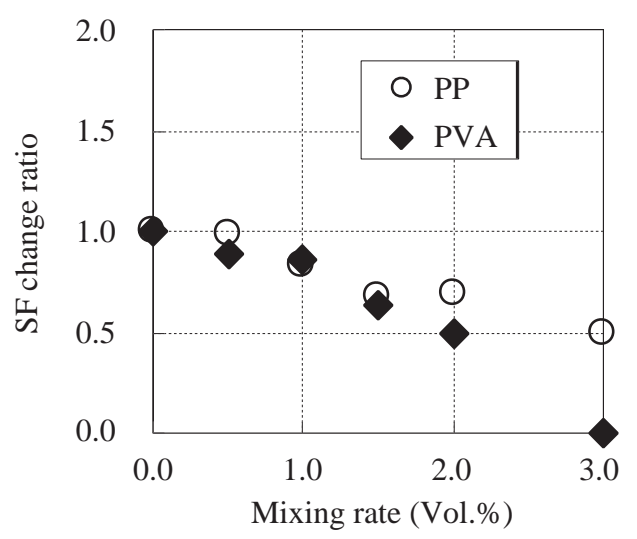

Fig. 4 Relationship between the SF change ratio and the mixing rate of the short fibers

setting the SF change ratio at about 0.5 , although the flow property falls with the increase in the mixing rate.

\subsection{Strength characteristic of short fiber reinforced concrete}

We carried out compression tests, direct tensile tests, and bending tests in order to examine the strength characteristics of short fiber reinforced concrete. In this paper, we report the results of the bending tests. Bending toughness is the important performance characteristic of precast concrete slabs. Figure 5 shows a bending test situation. The size of the beam specimen was $100 \times 100 \times$ $400 \mathrm{~mm}$. For the bending test method, JCI-SF4 [2] was

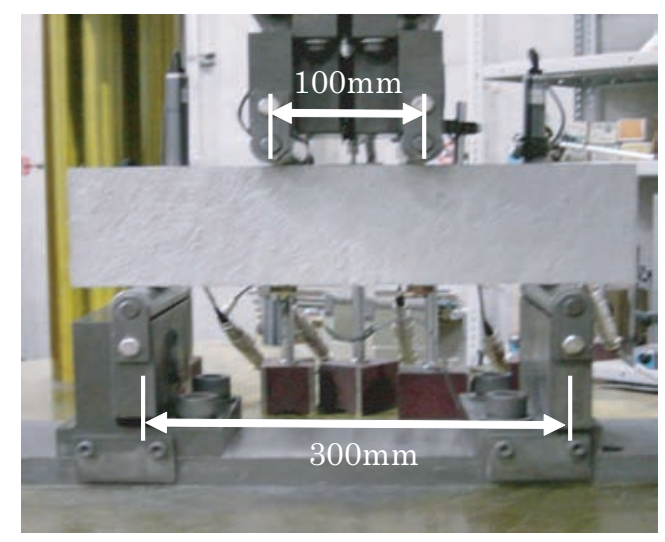

Fig. 5 Bending test situation 


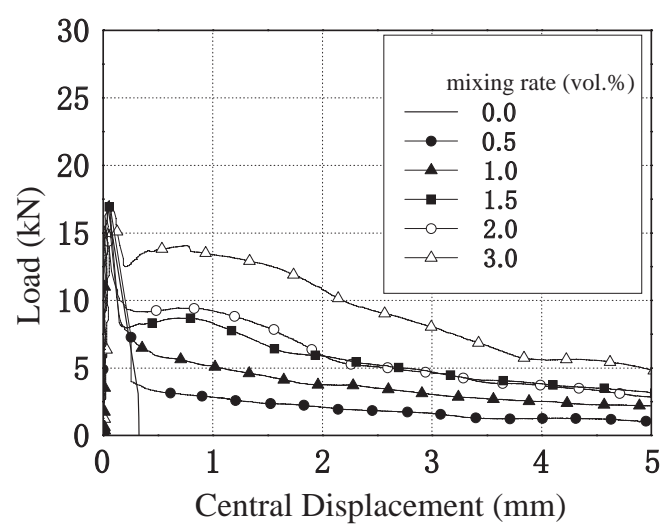

(a) PP short fiber

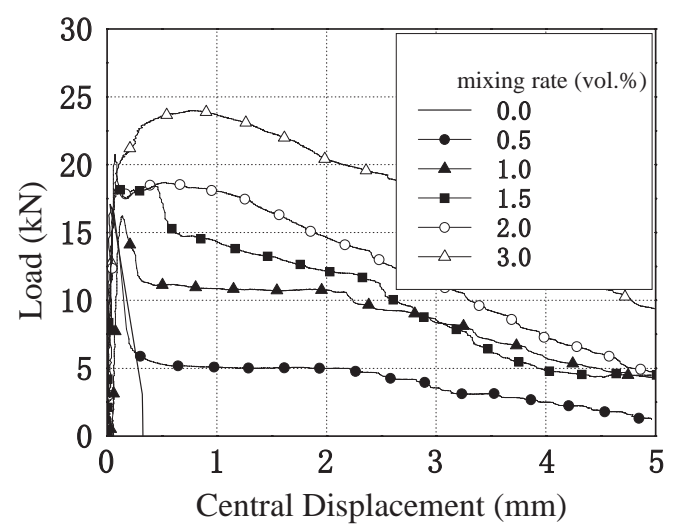

(b) PVA short fiber

Fig. 6 Relationship between loads and displacements of the center of beam specimen

adopted with the supporting point distance of $300 \mathrm{~mm}$ and a bending load interval of $100 \mathrm{~mm}$.

The mix proportion of the concrete and the mix rate of the short fibers are the same as those used for the flow property tests. Figure 6 shows the relationship between load and displacement of the center of the beam specimen for each mixing rate of the short fiber. From Fig. 6, it was confirmed that the increase in the mix rate of the short fibers reduces the fall of the load. That is, the increase of the mix rate in the short fibers improves bending toughness. Moreover, when two kinds of fibers were compared, the PVA fiber was better than the PP fiber with respect to bending toughness.

\subsection{Comprehensive evaluation of flow property and bending toughness.}

In order to evaluate synthetically the relationship between the flow property and the bending toughness of short fiber reinforced concrete, we calculated the area under the curve from 0 to $2 \mathrm{~mm}$ of central displacement and defined the calculated value as a bending toughness (Fig. 7) [2]. Figure 8 shows the relationship between the SF change ratio and the bending toughness. When the mixing rate of the short fibers was equal, the bending toughness of the PVA short fibers is better than the PP short fibers, although the flow property of the PVA short fibers is worse than that of the PP short fibers. From the findings obtained above, it can be concluded that the

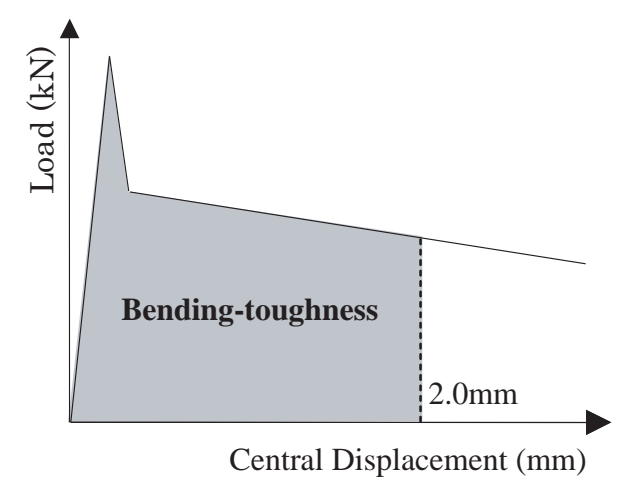

Fig. 7 Bending-toughness

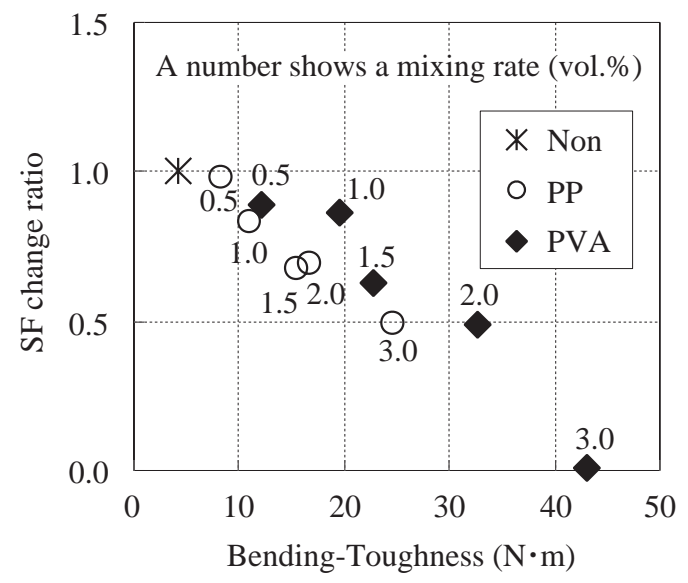

\section{Fig. 8 Relationship between the SF change ratio and the bending toughness}

evaluation by these two indices can be expected to be used as a tool by which we can choose the appropriate kind and amount of the short fibers according to a form of a structure and a construction method.

\section{Study of fatigue}

Generally the service life of precast concrete slabs is expected to be 50 years. As the number of train axles passing over a slab reaches 200 million or more during its service life, the study of fatigue failure is important for application of the precast concrete slabs with short fiber reinforced concrete. Therefore, it is necessary to establish the evaluation method of a fatigue failure. So we examined the results of the bending fatigue tests for short fiber reinforced concrete, and evaluated the fatigue life. The test specimens used in this study were made of concrete which is mixed with the PVA fiber of $2.0 \mathrm{vol}$ vol. $\%$.

\subsection{Bending fatigue tests}

The size of the test specimen used for the bending fatigue test was $100 \times 100 \times 400 \mathrm{~mm}$, the support span was $300 \mathrm{~mm}$ and the bending load interval was $100 \mathrm{~mm}$ as shown in Fig.5. Four kinds of cycle load, namely $15.7 \mathrm{kN}$, $17.2 \mathrm{kN}, 18.6 \mathrm{kN}$, and $20.0 \mathrm{kN}$ were applied, and the cycle frequency was $3 \mathrm{~Hz}$.

The compressive strength of concrete was $52.5 \mathrm{~N} / \mathrm{mm}^{2}$, 


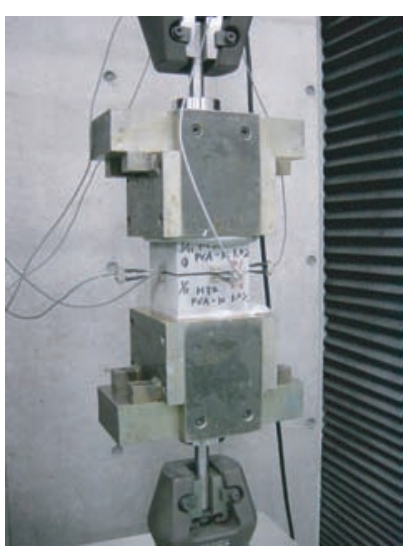

Fig. 9 Direct tensile test situation

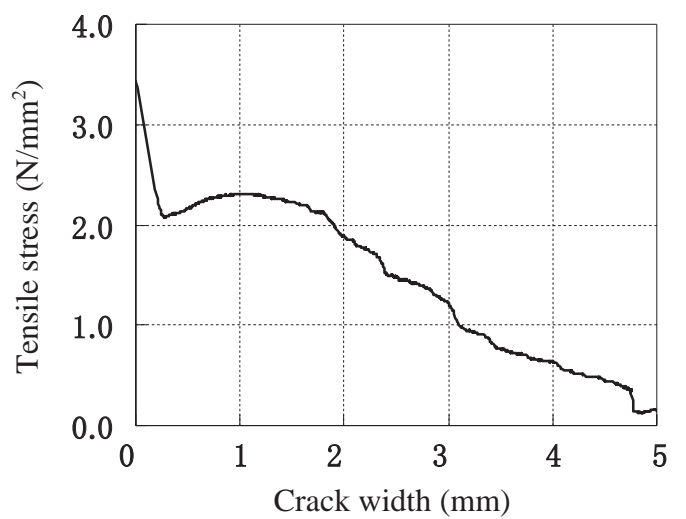

Fig. 10 Tension softening curve

and the tensile strength obtained from the direct tensile test (refer to Fig. 9) was $3.37 \mathrm{~N} / \mathrm{mm}^{2}$. The tension softening curve which is a result of a direct tensile test is shown in Fig. 10. As a result of the tests, tensile stress came down immediately after the start of cracking, and at the tensile stress of about $2.0 \mathrm{~N} / \mathrm{mm}^{2}$, the toughness action by the bridge effect of the short fibers was identified. Then, tensile stress declined gradually in correlation with broadening of the crack width.

Figure 11 shows the relationship between the bending fatigue life and the bending stress. The calculated

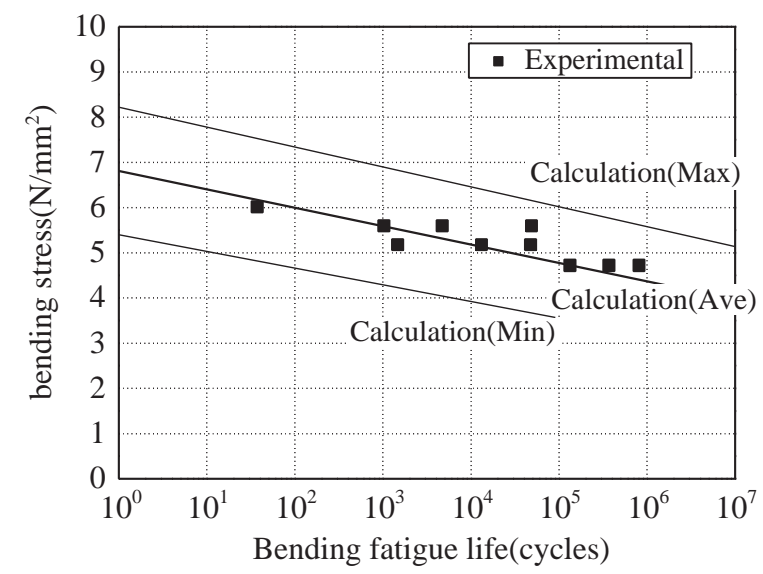

Fig. 11 Relationship between the bending fatigue life and the bending stress value of the bending fatigue life mentioned later is also shown in Fig. 11. The test results showed that the bending fatigue life of short fiber reinforced concrete increased in a linear relationship to the fall of the bending stress in a single logarithmic chart.

\subsection{The evaluation method of a bending fatigue life}

With regard to the influence of cycle load on the fatigue life of concrete, Horii et al [3] studied the growth of cracks by cycle load, and they reported that in the case of a brittle material like concrete, fatigue performance could be explained by crack growth.

Accordingly, in this report, we proposed a method of computing the bending fatigue life of the short fiber reinforced concrete from balanced design of a cross-section, taking the influence of the cycle load into consideration on the tension side, although without taking any influence of the cycle load on the compression side.

Figure 12 shows the flow of the calculation of the fatigue life. The fatigue life is computed by performing the balanced design of a cross-section to the bending moment by fatigue design load. Balanced design is repeated until the number of loading cycles reaches a steady value.

With respect to a compression model of the balanced design, the compression stress-distortion relationship shown in the Design Standards for Railway Structures Concrete Structures (hereinafter referred to as Concrete Standard) [4] was applied based on compressive strength obtained by a compression test. In addition, as the variation in material strength has a great influence on the result of fatigue tests, when calculating a fatigue life, three times the standard deviation was considered for variation in the compressive strength.

With respect to a tension model of the balanced design, the tension softening curve of Tri-Linear type (Fig 13) was established based on the experimental results (Fig $10)$, and the tensile stress of this model reduced accord-

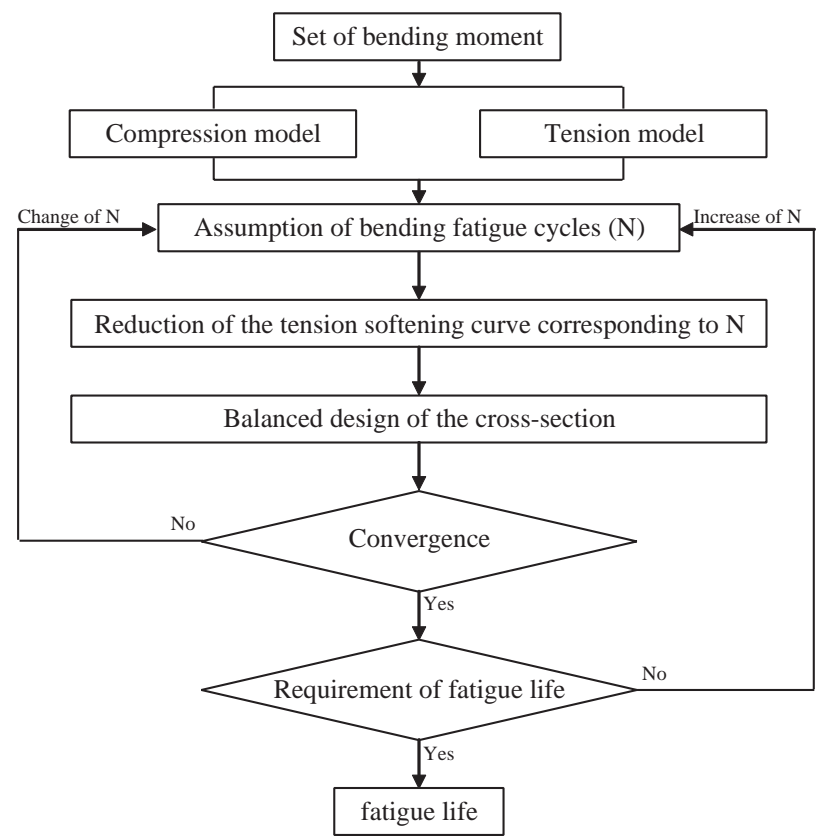

Fig. 12 Flow of the calculation for the fatigue life 


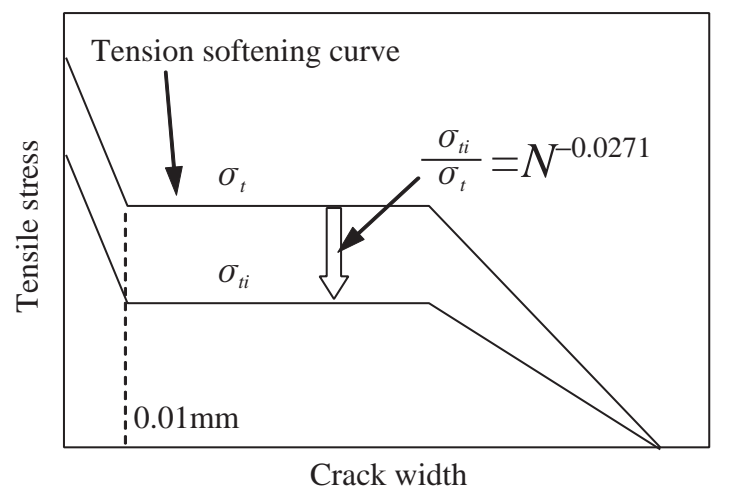

Fig. 13 Influence of cycle load on the tension model

ing to the increase in the number of loading cycles. We now explain the tension model in full detail.

The tensile stress declines until the width of the crack is $0.01 \mathrm{~mm}$ after reaching tensile strength. $0.01 \mathrm{~mm}$ was estimated from the tensile softening curve of plain concrete. The tensile stress declines to the stress $\left(\sigma_{t}\right)$ which the bridge effect of the short fibers causes, and the stress $\left(\sigma_{t}\right)$ is distributed in a crack area. In addition, because tensile strength was easily changed under various influences, we modified the tension softening curve by using the ratio of the tensile strength calculated by the Equation (2) to an experimental result. Moreover, the elastic modulus to tensile strength used the value shown in the Concrete Standard.

$$
f_{t}=0.23 f_{c}^{2 / 3}
$$

Since there is no clear variation in tensile strength different from compressive strength, we calculated tensile strength from the compressive strength by the Equation (2) with consideration of $\pm 3 \sigma$ for compressive strength, and we used this tensile strength for calculation of a fatigue life of short fiber reinforced concrete.

Next, the influence of the cycle load on the tension softening curve will be shown. According to fracture mechanics, fatigue failure of a concrete component is caused by the progress of a crack due to cycle load. Therefore, we thought that the progress of a crack was caused by degradation of tensile stress of a tension softening curve, and we assumed that a tension softening curve fell with the increase of the number of loading cycles according to the Equation (3) [5].

$$
\sigma_{t i} / \sigma_{t}=N^{(-0.0271)}
$$

\subsection{The calculation results of fatigue life}

The compressive strength of the short fiber reinforced concrete used for calculation of a fatigue life is $53.1 \mathrm{~N} /$ $\mathrm{mm} 2$, and the tension softening curve used is shown in Fig. 14. "Maximum" and "Minimum" which are shown in Fig. 14 are fixed, taking the variation in material strength into consideration. We calculated the fatigue life using the compression and the tension model, and compared the calculation result with the results of fatigue tests. Both results have been already compared in Fig. 11.

The results of the bending fatigue test were shown within the range between "Maximum" and "Minimum",

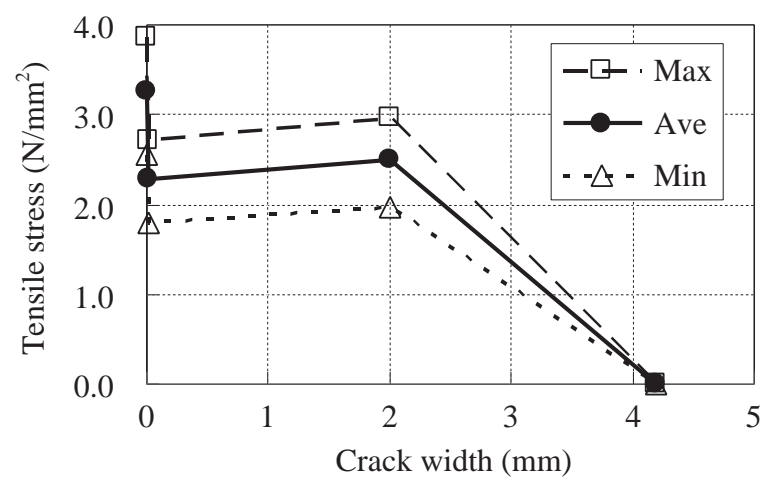

Fig. 14 Tension softening curve

and they also had high correlation with "Average". From the analysis above, it was confirmed that it was possible to calculate the fatigue life of staple reinforcement concrete by this method.

\section{Check test using a precast concrete slab of actual size}

We carried out the static bending tests and the bending fatigue tests with a specimen of the actual size precast concrete slab in order to check the performance regarding the bending and bending fatigue strength.

The specimen was made with the short fiber reinforced concrete which was mixed with PVA short fibers by $2.0 \mathrm{vol} . \%$. The specimen is of the form which was prepared by dividing the $\mathrm{RC}$ precast concrete slab into two in the direction of a rail $(200 \times 1170 \times 4930 \mathrm{~mm})$. In the bending test, the supporting point distance of the specimen was $3000 \mathrm{~mm}$ and bending load interval was 1000 $\mathrm{mm}$. The cycle loads of the bending fatigue test were 55.0 , $60.2,63.0$ and $74.5 \mathrm{kN}$. Therefore, the bending tension stresses at the bottom of the specimen were set to 3.5 , $3.9,4.0$ and $4.8 \mathrm{~N} / \mathrm{mm}^{2}$, assuming that all the sections of the specimen are effective.

Figure 15 shows the relationship between the bending tensile stress and the displacement which was obtained from the results of the static bending test. The

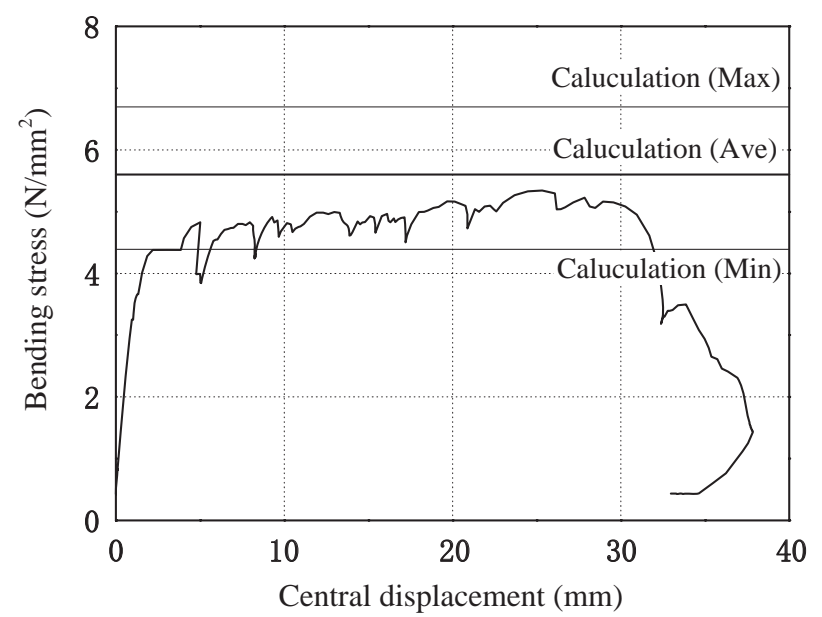

Fig. 15 Relationship between the bending tensile stress and the displacement 


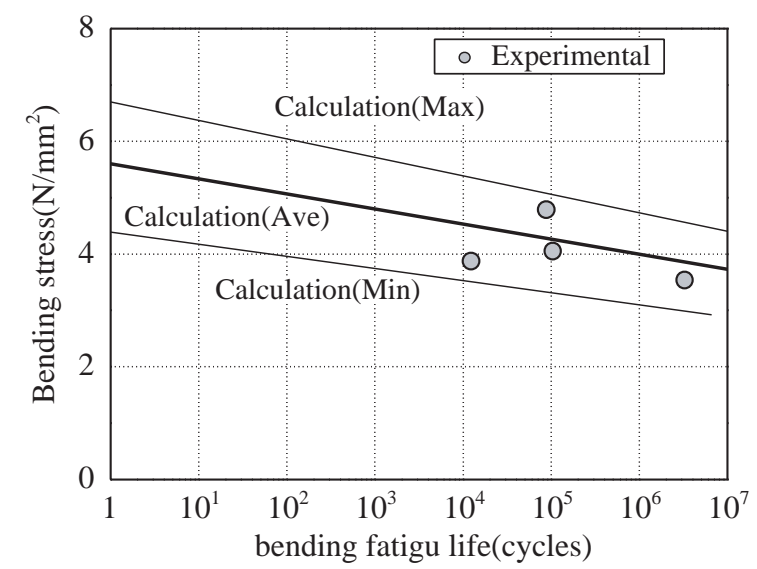

Fig. 16 Results of the fatigue life based on both bending fatigue test and calculation

bending tensile stress calculated by balanced design is also shown in Fig. 15. However, this bending stress is a value at the specimen bottom calculated from the bending moment when the strain of a compression edge is set to 0.0035 .

The result of the static bending test was in the range between "Maximum" and "Minimum" of the calculation values, and we confirmed that the bending fracture of precast concrete slab made from short fiber reinforced concrete could be verified by calculation.

Figure 16 shows the results of the fatigue life based on both bending fatigue tests and calculation. The test results in all cases were contained in the range of calculated results which were carried out with consideration of the variation in material strength. We confirmed that the bending fatigue of precast concrete slab made from short fiber reinforced concrete could be checked by this calculation.

In addition, a bending fracture load of the actual size precast concrete slab by the static bending test was about $80 \mathrm{kN}$, and this value was larger than the load $(43.6 \mathrm{kN})$ corresponding to the bending moment $(21.8 \mathrm{kN} \cdot \mathrm{m})$ used for the design of bending fracture. Moreover, it is thought that the load corresponding to the bending moment used for the design of bending fatigue fracture is $21.2 \mathrm{kN}$, and this load, which is below the bending crack load, will not cause fatigue fracture by its repetition.

\section{Performance of environment}

In order to inquire into frost damage, we carried out a freezing and thawing test [6] of short fiber reinforced concrete which was mixed with the PVA fiber by 2.0 vol. $\%$. $\mathrm{W} / \mathrm{C}$ of concrete was $47.0 \%$.

Figure 17 shows the test results of relative dynamic modulus of elasticity for 300 cycles of freezing and thawing. Although the relative dynamic modulus fell a little in the early stages of the cycle, it was kept at about $95 \%$ until 300 cycles. Since this value exceeded $85 \%$, which is the severest condition shown in the Concrete Standard, the short fiber reinforced concrete has sufficient performance with respect to freezing / thawing cycles. Although the examination about damage due to salt water was not

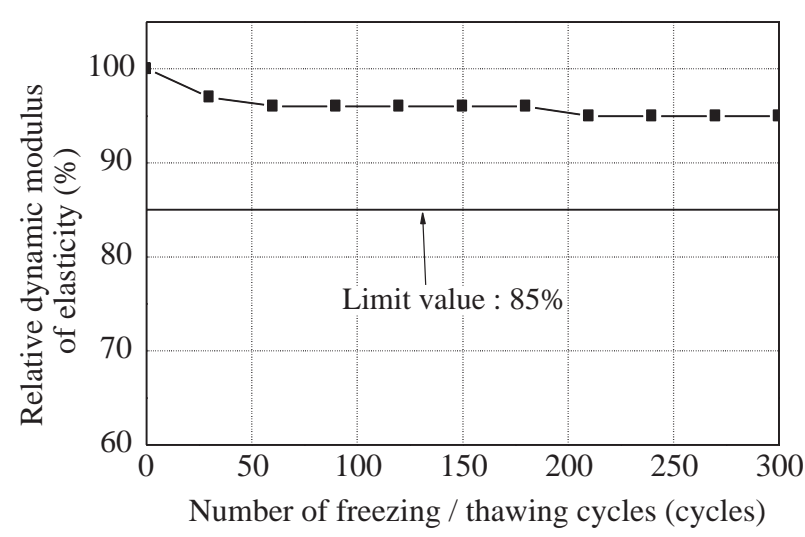

Fig. 17 Result of the freezing and thawing test

carried out, the short fiber reinforced concrete should have sufficient durability against damage from salt water since the rebar is not used for reinforcement of concrete.

\section{Conclusions}

The main results obtained in this research are as follows:

1) In this case of more than 0.5 of slump flow change ratio, the flow property of short fiber reinforced concrete can be sufficient. Also, in case the mixing rates of PVA short fiber is equal to those of PP short fiber, the PVA short fiber was more effective for increasing bending toughness.

2) From the aspects of bending failure and bending fatigue failure, the short fiber reinforced concrete has enough function to be applied to precast concrete slabs for slab tracks.

3) By repeating balance calculation of the section using the tension softening curve in consideration of the influence of cycle load, the fatigue life of the short fiber reinforced concrete can be predicted.

4) The possibility of the short fiber reinforced concrete to withstand damage from salt water and frost was indicated.

\section{Acknowledgements}

This study is results of the joint research of Kuraray Co., Ltd, Tekken Co., Ltd, and Railway Technical Research Institute.

This study was supported by Mr. Watanabe at Hokubu Consultant Co,.LTD. The authors would like to express sincere appreciation for his cooperation.

\section{References}

[1] Ogawa, A., Suemori, H., Saitou, T., and Victol, C.Li., "Experimental Research about the Flow Property of the High Toughness Short Fiber Reinforced Concrete which used the PVA Fiber," Proceeding of the Japan Concrete Institute, Vol.23, No.1, pp.73-78, 2001 (in Japanese). 
[2] Japan Concrete Institute: Standard about the Test Method of Fiber Reinforcement Concrete (JCI-SF4) Bending Strength and Bending Toughness Test Method of Fiber Reinforced Concrete, 1984 (in Japanese).

[3] Horii, H., Shin, H. C., and Pallewatta, T. M., "Mechanism of Fatigue Crack Growth in Concrete," Cement \& Concrete Composites 14, pp.83-89, 1992.

[4] Railway Technical Research Institute, "Design Standards for Railway Structures - Concrete Structures,"
Maruzen 2004.

[5] Masuda, A., Ozawa, K., Matsuoka, S., "Research on Bending Fatigue Fracture of Concrete Component," Proceeding of the Japan Concrete Institute, Vol.24, No.2, pp.955-960, 2002 (in Japanese).

[6] Japanese Industrial Standards Committee: Method of Test for Resistance of Concrete to Freezing and Thawing (JIS A 1148), Japanese Industrial Standards Committee (in Japanese). 